\title{
Experimentation with Organisation Analyser, a tool for the study of decision making networks in organisations
}

\author{
Frédéric Adam \\ College Lecturer, Dept. of Accounting, Finance and Information \\ Systems, University College Cork, Western Road, Cork, Ireland \\ Tel: 35321904038
}

Fax: 35321271566

Email: ster8004@iruccvax.ucc.ie

\begin{abstract}
This paper reports on experimentation with Organisation Analyser (OA), a prototype software aimed at supporting the identification and analysis of decision making networks in organisations. Previous research has identified that there was great benefit in adopting a network approach to the study of organisations. This research has viewed organisations as being composed of a variety of different types of networks: emergent networks, established networks, communication networks, grape vine etc. However, it is often difficult to operationalise such an approach when studying such complex phenomena as organisational decision making and implementation.

To facilitate the application of network analysis to entire organisations, we have developed Organisation Analyser (OA), a Windows-based tool for the representation and analysis of all the relevant kinds of networks which we tested in one Irish organisation. Central focus on a sample of decisions currently being made and implemented in that organisation brought to light the very political and unstable nature of the objectives and the unfolding of the decisionmaking processes in organisations. With the help of a novel framework for the analysis of organisational decision making, this paper describes the organisation where the research is taking place and the decisions selected for the purpose of the study. It shows the support which OA provided the researcher in the analysis of the information collected and presents preliminary conclusions regarding the nature of the decision making effected by groups of top managers in organisations and the way in which these decisions are implemented. In particular, it provides new insights into the concepts of structural hole, centrality and decision ownership. It reveals how decision implementation can be just as difficult as choice. OA appears to have potential as a DSS tool to assist managers in structuring their organisational networks better.
\end{abstract}

\section{Keywords}

AC402 Group decision making, AC403 organisational decision making, AD 102 information in organisations, AD04 information channels 


\section{CASE STUDY OF A DECISION PROCESS}

In March 1995, Fun Ireland Ltd, a toy company based in Ireland and the subsidiary of a large American corporation, were trying to purchase an integrated software package which would cover the financial, distribution and manufacturing aspects of their business. The business was growing rapidly on all their European markets and they were also looking into expanding into a number of South American countries. They had been a mainly manufacturing organisation, but now 75\% of their turnover was coming from trading goods produced by their suppliers in the Far East.

They had been telling their parent company about the failure of their current, largely manual systems for a long time, but everytime they had asked for clearance to purchase any system, it had been refused by the $H Q$ in New York. At that time, Fun only had a few PCs on which a large number of spreadsheet reports were being produced covering most aspects of the business. They also had a payroll and an inventory control system that was provided to them by a supplier of computer bureau services. However, that software and the PDP 11 computer running it were now completely obsolete and Fun were the last customer using a service which was becoming more and more expensive and unreliable.

Dave, the finance director of Fun had been wrestling with the problem ever since he had joined the company 18 months earlier and had identified the potential failures threatening to occur in many areas. Sales order processing was his main concern as he was convinced that Fun was losing a significant portion of the ever growing business due to orders not being met on time or being forgotten about. But invoicing was crucial too and he wondered how long it would take before customers realised that Fun sometimes had no clear idea how much had been shipped to a particular customer.

After one year of work and a number of rejections from the US on technical grounds, Dave decided to hire a consultant in this area to help him produce the reports that would convince people at the HQ to give the go ahead. He got in contact with a research centre in the local university and started working with Brian, one of their researcher / lecturers.

Brian took four weeks to carry out an extensive analysis of requirements in Fun and to draw the outline of the systems required. In the report he wrote, he also pointed out the numerous weaknesses in the current systems. This report was presented to the top managers in Fun and the recommendations were approved. It was also forwarded to the HQ in the US who merely acknowledged reception. Brian then put together an Invitation to Tender which was sent to six potential suppliers of systems, of which four responded within the time allocated. Based on these proposals, Brian and Dave selected two organisations with which they pursued contacts including a formal presentation of their proposed solution and a visit of their premises. Both turned out to be local suppliers and that was largely due to Brian's perception that local support would be a very important asset during the implementation phase as people in Fun has little experience with large computer systems (there were no IT personnel in Fun at that time). They eventually selected one supplier who made a final presentation to the top management of Fun and received the approval of the Managing Director. The next step was to commit the money to this investment of roughly $£ 150,000$ and the signs were good when the IT Director at the HQ (the one who had stopped the investment until then) responded favourably to the request and agreed with the conclusions of the final 
report he had been sent. All that was now needed after 20 months of the decision making process was a signature of the finance Director at the $H Q$.

In the meantime, Fun's parent company had purchased Kiddies Clothing Ltd; a UK-based company similar in size to Fun but operating in a complementary market. Because of the numerous uncertainties regarding the sharing of business between Fun and Kiddies and the relations to be developed between the two companies, the $H Q$ blocked the investment in Fun.

The bad news infuriated Dave who had put so many efforts into the whole project over a two year period. Brian helped him find his second wind and initiate a number of meetings with equivalent personnel in Kiddies and a new strand of reports were sent to the $H Q$ to indicate how the systems in Fun and Kiddies would operate and the processes that would be shared between the two companies. A joint report signed by Fun and Kiddies was even sent to the US which emphasised the support that Kiddies were ready to give Fun in their implementation of the system that Brian and Dave had selected.

Still, after two more months of negotiating with people at the $H Q$, the request to commit the money was rejected and the whole project put on hold while a global IT strategy for Fun was put together by the IT director at the HQ. More than two years after the first alarming reports had been written and sent to the US about the weaknesses of the current systems in Fun, nothing had been done and the manual systems were still holding on. A computerised system for Fun Ireland had never seemed so far away.

This ultimate reversal of fortune discouraged Dave who was beginning to think that history was just going to repeat itself over and over again. But Brian found it difficult to accept that all the efforts of the last few months had been in vain. In an attempt to demonstrate that there were no managerial grounds for postponing any longer the commitment of Fun to the purchase of a platform and a software that had already been carefully selected, he convinced Dave and Mark to send a final report to the HQ. In this report, they particularly emphasised that a global IT strategy for the company made little sense as no truly shared processes requiring integration of computer systems had been identified either between Ireland and the US or between Fun and Kiddies. In addition, the implementation of such global strategy meant that Fun would have to sacrifice the possibility of using local support for the software, an added difficulty for a company without full-time resident IT expertise.

Much to their surprise, this report was to win them the battle. Mid-way through December 1995, Dave got the news that he could start implementing the decision to purchase an integrated computer system covering the financial and distribution activities of Fun. Before the end of January, the cabling had been put in place and discussions were on-going regarding the choice of a file server.

However, the implementation of the decision proved as difficult as the previous stages and Dave has to clear each purchase with the HQ. At times, it seems that the reluctance to implement the choices that have been made is as great as the reluctance to commit to these choices in the first instance. For Brian, who is now watching from the outside, there seems to be a risk that the whole process is further delayed at every stage of the implementation just as it has been in the earlier stages of the decision process. Implementing the project - actually spending the money - is even more difficult than planning - merely thinking about spending the money. Moreover, it appears that committing to a solution is not the most important aspects of decision making; implementing it, enacting the choices made, raises new issues and fresh interrogations which were overlooked or ignored throughout the previous stages. 
The short scenario presented in the previous paragraphs is in no way an invention, it is the true story of a still unfinished decision process in which the author of this paper played the role of the consultant ${ }^{1}$. This story illustrates that the decision making processes used in organisations are on average very remote from the normative models prescribed by such areas of research as economics where actors seek to maximise their utility or their profit (Simon, 1955). People in organisations might attempt to behave in a way that optimises the outcomes of their decisions, ie 'rationally', (even though this has been questioned as well, eg: Feldman and March, 1981), but at the overall level of an organisation, the processes used and outcomes reached can appear very difficult to understand and follow for an outside observer. This has already been reported in the literature. March (1987) has described how the available empirical studies of decision making processes in organisations indicate that our current theories of choice overestimate the coherence of decision processes. In the case of Fun, both Dave and the people he was negotiating with in the HQ are following their own agendas and use everything in their power to convince the other managers that they are correct. But, seen from the outside, the two and a half year decision making process appears to be totally illogical and wasteful of people's time and energy, as a decision was reached several times during the period covered by the study, but kept being rejected until finally, it began being implemented as in slow motion. The fact that this case deals with the subsidiary of a multi-national company with limited autonomy for investment matters does not provide sufficient explanation for these decisional uncertainties as all managers involved agree on the nature of the problems and the goals of the project. It confirms that decision processes can sometimes appear to be without any order (March and Olsen 1986) and that the preferences of managers are often vague and contradictory, even when there is agreement on the overall objectives (March, 1987). Indeed, Keen (1977) has explained how decisions must often satisfy contradictory objectives whose relative priorities evolve over time. In addition, fresh questions seem to arise at the implementation stage of the decision making process which makes little managerial sense in the light of the traditional literature on normative decision making.

This paper reports on an experiment with a new way of studying the complex processes leading to the making and implementation of decisions in organisations and attempts to bring together results and observations of the behaviour of individuals, groups and sub-units within organisations to compare them with the resulting organisational processes. We use the data collected in a case study of multiple decision processes in an Irish organisation to test the validity of the network approach - a technique borrowed from the field of Sociology - to the study of decision-related tasks in real organisational settings.

\section{ANALYTICAL LEVELS IN THE STUDY OF DECISION MAKING}

As is demonstrated in the case study presented in this paper, it is difficult to establish a clear link between individual behaviour and the resulting organisational processes. This was observed by many previous researchers and research on the behaviour of people when they are associated with others has started as early as the 19th century. Gustave Le Bon (1896) has investigated the psychology of the 'Crowd', which he described as behaving like a single being

\footnotetext{
${ }^{1}$ The names of the organisations and the people studied in this case study have been changed to enable a more complete reporting of the behaviour of the actors and the context of the decisions.
} 
subjected to 'the law of mental unity of crowds'. Individuals in crowd, says Le Bon, lose their conscious personality and adopt and follow a sort of collective mind. McGrath (1984), whose work on groups is often used as a reference, indicated how important groups are for organisations. He said that "groups are the instruments through which much work gets done" (McGrath, 1984: p 5) and Pennings concluded that:

People (...) do not exist in a social vacuum; they are surrounded by fellow members and are embedded in a network of social relationships. They are also often associated with decision making groups such as work teams, budget committees, board of Directors (...). Groups are an important medium through which decisions are made and can greatly affect the way individuals arrive at decisions [Pennings, 1983 : vii].

Many empirical findings have emerged in this respect from the extensive study of a large variety of actual groups in society and in organisations. However, many researchers have argued that focusing on groups is not sufficient in the context of the study of managers' work. It seems that much of the interactions between managers may escape the notion of group. For example, previous studies of information exchange amongst managers involved many types of interaction between the managers of an organisation (Adam and Murphy, 1995 a; Daft et al., 1988; Jones et al., 1988), whereas much of the group research has focused on what happens within formalised groups where members know they are part of a group. As a result, the focus of the group research field has now shifted significantly as researchers turned to other analytical levels and other unit of analysis, namely the individual and the organisation.

In sociology, the need for additional analytical levels besides the individual and the group levels were also identified (Monge and Eisenberg, 1987). For example, Burt (1980) has described the personal level, the 'clique' level and the overall organisational network level, while Tichy (1981) has added a fourth level: the environmental or inter-organisational level. In support of such attempts to experiment with more realistic (but more complex) analytical levels, Hedberg pointed out that
Although organisational learning occurs through individuals, it would be a mistake to conclude that organisational learning is nothing but the cumulative result of their members' learning. Organisations (...) have cognitive systems and memories. As individuals develop their personalities, personal habits and beliefs over time, organisations develop world views and ideologies. Members come and go, and leadership changes, but organisations' memories preserve certain behaviours, mental maps, norms and values over time. [Hedberg, 1981:6].

Thus, for this study, it is proposed to differentiate between the different levels at which interaction takes place among managers in organisations as a vehicle to support our study of organisational decision making. The contention is that any study of managerial activities must articulate what processes are used (1) by individuals, (2) by spontaneous groups of the kind that exist when managers form informal associations to tackle specific problems, (3) by identified groups, such as Steering Committees or Boards of Directors and (4) by the organisation as a whole (Adam and Murphy, 1995b). In the context of this study, the aim was to trace the decision-related activities accomplished at each of the four levels identified as relevant analytically and the decision-related activities which span several or all of these levels. 
The network approach to organisations already used in sociology (Roethlisberger, 1977) seems to offer a mode of organisational inquiry which can accommodate the different analytical levels required for the study of organisational phenomena such as decision making and implementation (Nohria, 1992).

\section{THE NETWORK APPROACH TO ORGANISATIONS - A NEW MODE OF INQUIRY FOR IS}

Roethlisberger expressed the view that organisations and behaviour within them were such 'elusive phenomena' that no research should aim at providing a definitive theory for the study of organisations. He proposed that a framework that could be used as a 'walking stick' to investigate the field of organisational research would be more useful (Roethlisberger, 1977). Nohria has suggested that Network Analysis, a body of research which concentrates on networks defined as 'the observed pattern of organisation' can be such a walking stick 'likely to hold well in our intellectual inquiry of organisations' (Nohria, 1992).

Since the 50's the concept of networks has been used in a number of fields as diverse as psychology, sociology and molecular biology. Roethlisberger and Dickson (1939) used it in the 30's to emphasise the importance of people's webs of informal relations in organisations. Thus, the network perspective is born out of a careful observation of the life of actual organisations. Balbridge has observed that New York University makes decisions through 'a network that allows a cumulative build-up of expertise and advice' (Balbridge, 1971) while Kadushin observed that 'a core of 47 people (...) runs Detroit' (Kadushin, 1978). The work accomplished has enabled the capture of a number of significant organisational processes at different levels of analysis, i.e.: individual, groups, cliques, sub-units and organisation as a whole (Tichy, 1992).

This more realistic approach to organisations has been formally described by Nohria. He suggested a dynamic approach to the analysis of organisations whereby actors (or managers)

are not seen as atoms locked in a crystalline grid, their every action determined by their structural location, (...)[but as] active, purposeful agents' [Nohria, 1992].

White indicated that individual ties are continuously added to and subtracted from formal networks as managers get involved in different projects or face different problems and he described management as an on-going process involving

throwing up fresh network and changing existing networks (...) whole chunks of networks are added or rearranged in concert. Reorganisation never ends because struggles for control never end [White, 1992: 94].

Thus, the analysis of organisational networks examines the structure and patterning of relationship that establish amongst individuals and groups in organisations and attempts to draw conclusions for the study of individual behaviour in organisations. We intend to apply it to the study of decision making and decision implementation with the support of a computerbased tool developed especially for this research project. 


\section{OPERATING PRINCIPLES OF ORGANISATION ANALYSER}

Because the principles of network analysis are not self evident when it comes to their operational application to studying decision making processes, the first step in this research project was to develop a computer-based tool called Organisation Analyser which would support the analysis of the different networks existing in the organisations studied at the different levels of analysis identified in section 2 of this paper.

Organisation Analyser (OA) uses the principles of message flow analysis (Stohl and Redding, 1987; O'Reilly, Chatman and Anderson, 1987). This research has demonstrated that the communication which is so crucial for organisations cannot exist without messages, these stimuli that 'trigger a meaning in someone's head' (Stohl and Redding, 1987). OA is focused on the study of the interaction between individuals and it uses messages as an indicator of such interaction. It helps researchers identify the mechanisms used for the transmission of typical messages between individuals (communication channels, frequency of interaction, nature of relationships) and concentrate on what it all means for organisational decision making.

$\mathrm{OA}$ also uses the principles of network analysis regarding the relative positions of individuals in organisational networks. Researchers who analysed organisational networks identified a number of standard individual roles that individuals can have: the stars, the linkers (or bridges) and the isolates (Monge and Eisenberg, 1987). They have also showed that individuals can be more or less central in a communication network: (1) central because they are involved in many relations, (2) central by betweenness because they are in the middle of paths that connect others or (3) central by closeness because they have immediate access to others who are connected (Brass and Burkart, 1992). According to Brass and Burkart, all these aspects of centrality are important to identify because they can confer a different basis of power. Granovetter (1973) and Burt (1992) have also argued that people who surround themselves with 'structural holes' (areas of an organisation where contacts between people or groups are disorganised) gain additional power and autonomy.

It can prove difficult to identify managers' degree of centrality and their position relative to structural holes in organisational networks because the complexity of these networks often makes it difficult to examine the whole network or to envisage all its characteristics at the same time. OA enables researchers to collect from managers large amounts of data regarding managers and their linkages to each others but also regarding the usage of the information exchanged and the managerial activities served by these transfers of information. It then provides a means to store all these data into a stable, but meaningful model of the organisation. It is therefore possible to visualise the networks and the relative strength of the linkages between managers in the stable environment provided by the software and to investigate what happens within the network as the organisation tackles a decision situation.

To support these goal, OA enables the creation of a number of objects: (1) managers, (2) groups, (3) internal links, (4) external links, (5) interdependencies and (6) decisions. The researcher can store the personal data required to identify each actor including their perception of their role, their goal within the organisation and their perceived environment uncertainty (Daft, Sormunen and Parks; 1988). Managers are visually represented by special icons as in Figure 1. Links between managers and their information content can be described as being emergent or formal (Monge and Eisenberg, 1987; Euske and Roberts, 1987), as communication or information oriented (Adam and Murphy, 1995a), as carrying primarily hard 
or soft information (Mintzberg, 1973); task related or non task related information (Bales, 1953, 1950); routine or unexpected information (Huber, 1982; Huber and McDaniel, 1986) and internal or external information (Blandin and Brown, 1977; Kefalas, 1973; Keegan, 1974). OA also uses Daft and Lengel's framework of communication channels to classify the media used in relationships (Daft and Lengel, 1986).

A special type of link with the environment can be attached to managers. It allows the same level of coding as with a normal link, but managers in contact with their environment are flagged by OA with a special icon as seen on Figure 1 (manager 1 and 2).

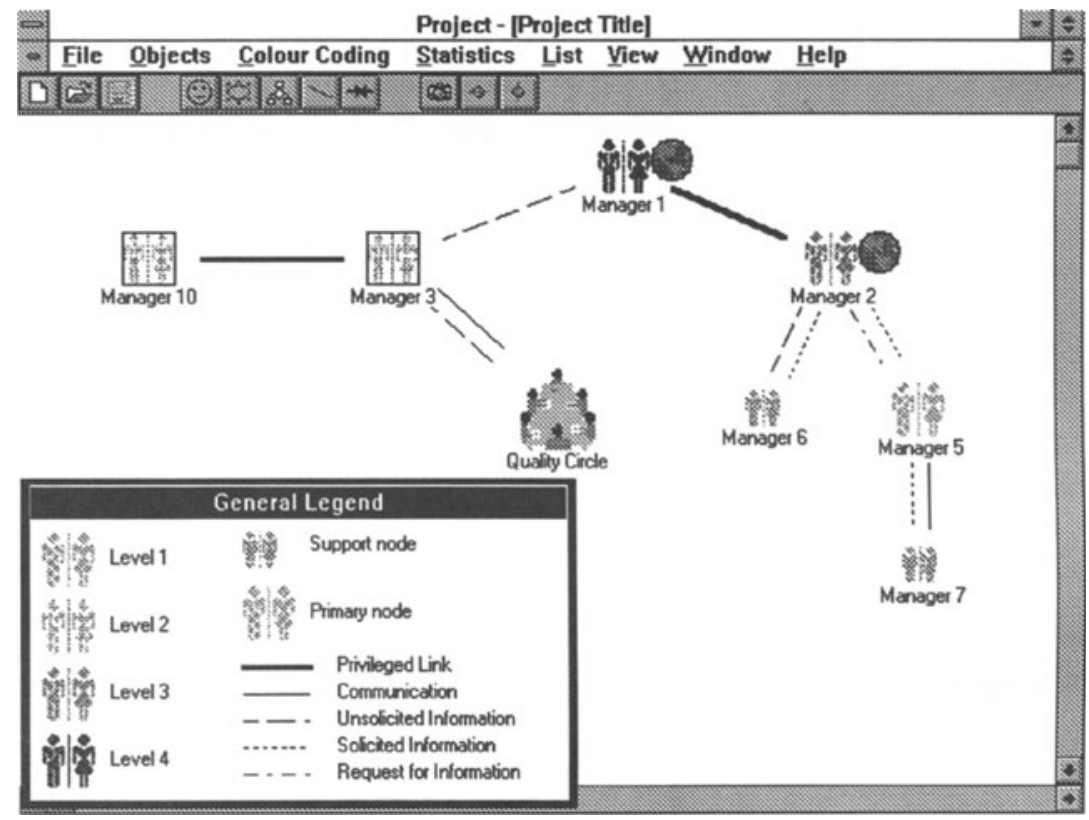

Figure 1 The main screen of $\mathrm{OA}$ with a sample of six managers

Note: The explanation of the legend in Figure 1 is given in section 5 of this paper

Groups can also be coded in OA by selecting the managers involved and assigning them the status of group. These groups can then be visualised by changing the view mode of OA to 'groups'. Groups are coded with a specific icon and an attached label (Figure 1 - quality circle).

Once the data collection steps have been accomplished, researchers can use the multiple analytical features of OA to obtain quickly a very high level of aggregation in the presentation of the data thanks to a number of built-in filters. For example, the user can get a visual breakdown of all the links used by the managers which differentiates between communication links, request for information, unsolicited information etc. Figure 1 shows the different types of links used by a sample of six managers. Other analytical filters that can be applied to the 
organisation analysed include a breakdown of the communication media used by the managers; a breakdown of the frequency of the interaction between the managers; channels used for the different types of information; new versus established channels of interaction and a hierarchical filter which maps the distribution of managers within the organisation by hierarchical level and by functional area.

Finally, OA enables the researchers to analyse the way in which managers use their information. The current prototype focuses on decisions made by individual managers and by groups as a way to discover how executives work out common visions of their world. Any number of actors can be attached to each decision, and actors may be assigned to a particular phase of the decision process (Mintzberg et al., 1976; Simon, 1977).

\section{THE STUDY AT FUN}

The study of the decision making processes used in an organisation requires some form of classification of the different types of decisions with which managers can be faced. This must enable the selection of a meaningful sample of decisions representative of the decision making of that organisation (Keen and Scott Morton, 1978). A number of parameters can be put forward to differentiate amongst decision types such as: (1) the type, frequency, structure and complexity of the decision; (2) the characteristics, capabilities and needs of the decision maker; and (3) the organisational context (Keen and Scott Morton, 1978). A number of frameworks have been put forward to deal with this complexity (Gorry and Scott Morton, 1971, Moore and Chang, 1983, Adam et al., 1995).

Adam, Fahy and Murphy (1995) have summarised much of the work carried out thus far in this area. Based on this review of existing research, they have identified that the novelty of the problem and its specificity appear to influence the processes used by managers when making a decision. Novelty in this instance refers to the prior experience which management have with a certain type of problem in a given organisation. March and Olsen have suggested that novelty is not a property of a situation so much as it is people's reaction to it; and the most common organisational response to novelty is to find a set of existing practices that can be used (March and Olsen, 1989). Thus, organisations, while relying on a limited set of 'stable, routine processes', are able to tackle a wide variety of new situations and give the impression that they changed themselves drastically to adapt to modifications in their environment (March, 1981).

The second factor, the specificity of the problem, is partially related to the first. It relates to the ability of management to set out the appropriate specifications for the problem they face and the information that they need to address the problem raised by a particular decision. This factor is problematic because the definition of problems is as much a human construct as the solutions of these solutions (Lévine and Pomerol, 1995; Pomerol, 1994).

Adam et al. (1995) formalised these comments in a framework of decision types which allows for an organisation's specific experience of dealing with the different types of problems and takes into account that the level of expertise of management in organisations may evolve over time. When decision situations are faced a certain number of times, managers' ability to tackle them may increase and, in any case, their ability to describe the cause and effects relationships between the parameters of the decision increases (and so does the level of specificity of these problems). Thus, the decision making processes used by managers will 
become more and more refined as their experience with the decision situation they address develops and the implementation of these decisions becomes more and more routine and automatic.

For the purpose of this study, Adam et al.'s framework was simplified to support the selection of a sample of decisions representative of the decision making of managers in Fun Ireland Ltd (see Table 1).

Table 1 Decision situations studied in Fun Ireland Ltd.

\begin{tabular}{llll}
\hline & $\begin{array}{l}\text { Complete model } \\
\text { available }\end{array}$ & $\begin{array}{l}\text { Partial model } \\
\text { available }\end{array}$ & No model available \\
\hline $\begin{array}{l}\text { Has happened } \\
\text { before }\end{array}$ & $\begin{array}{l}\text { Ordering goods } \\
\text { from far east } \\
\text { suppliers }\end{array}$ & $\begin{array}{l}\text { Introduction of an } \\
\text { existing product on }\end{array}$ & $\begin{array}{l}\text { Development of a } \\
\text { new entertainment } \\
\text { product }\end{array}$ \\
\hline $\begin{array}{l}\text { Has never } \\
\text { happened before }\end{array}$ & $\begin{array}{l}\text { Selection of an } \\
\text { automatic }\end{array}$ & $\begin{array}{l}\text { Selection and } \\
\text { implementation of }\end{array}$ & $\begin{array}{l}\text { Acquisition of } \\
\text { another company }\end{array}$ \\
& telephone system & an integrated CBIS & in Europe \\
\hline
\end{tabular}

At the time this study began, the researcher already possessed a significant knowledge of the organisation studied thanks to the consultancy exercise described in section 1 . This enabled the selection of the decisions in table 1. The next step consisted in interviewing all the actors involved in these decisions and the coding of the resulting data in OA for analysis. The results of this analysis are presented in the section below.

\section{The Decision Groups at Fun}

Organisation Analyser was used to study the managerial groups and the external agents involved in the decision making processes selected in Fun. First, the overall network was roughly coded starting from the Managing Director down through four layers of personnel, then the sub-sets of this network involved with each of the decisions were isolated and refined in light of the specific decision process they supported. Figure 2 shows the people involved in the integrated Computer-Based Information System (CBIS) selection decision described in the introduction of this paper in the different organisations to which they belong: Fun' people in Ireland (A) and in the Headquarters in the US (B), Kiddies' people (C), the consultant (D) and the vendor of systems (E). The clear focus on this particular decision is justified by the greater knowledge and the longitudinal exposure of the researcher to this decision situation.

Figure 2 shows in details the relationships existing between the people involved in the context of this decision. The thicker lines represent privileged links between nodes in the network whereby the people connected have full access to each other, share information on a equal basis and exchange opinions freely. This was the case, for instance, between Brian (the consultant), Dave (the project leader for Fun) and Mark (the accountant of Fun) who were at the core of the project and were the most active in designing potential solutions and producing reports for the others. The thin lines represent the communication links whereby people are in contact with each other in the context of the decision and exchange information and opinions at regular intervals or on an ad-hoc basis. This was the most common type of link identified between the people involved. 
Finally, the dotted lines indicate a different kind of relationships where one manager is clearly subordinated to the other. The most fundamental characteristic of these relationships is that they are asymmetrical as opposed to the symmetrical (like the previous two kinds: privileged links and communication links). More specifically, relationships coded by double dashed lines indicate requests for information from the superior toward his/her subordinates and the resulting flow of requested information. In the case of Dave (the project leader for Fun in Ireland) and John (the Chairman of the Board of the parent company), a flow of unsolicited information (long dashes line) what also coded to account for the many reports Dave sent John to try and influence his decision making regarding the system. Very often, these relationships go by two as one manager report to the other. The only exceptions concerned Peter (the project leader for the software vendor) who kept sending unsolicited information to Brian to provide him with stronger arguments in favour of the system and Dave who was trying to persuade Veronica to clear the investment. Such flows of unsolicited information were often the mark of intense lobbying of top managers by lower levels.

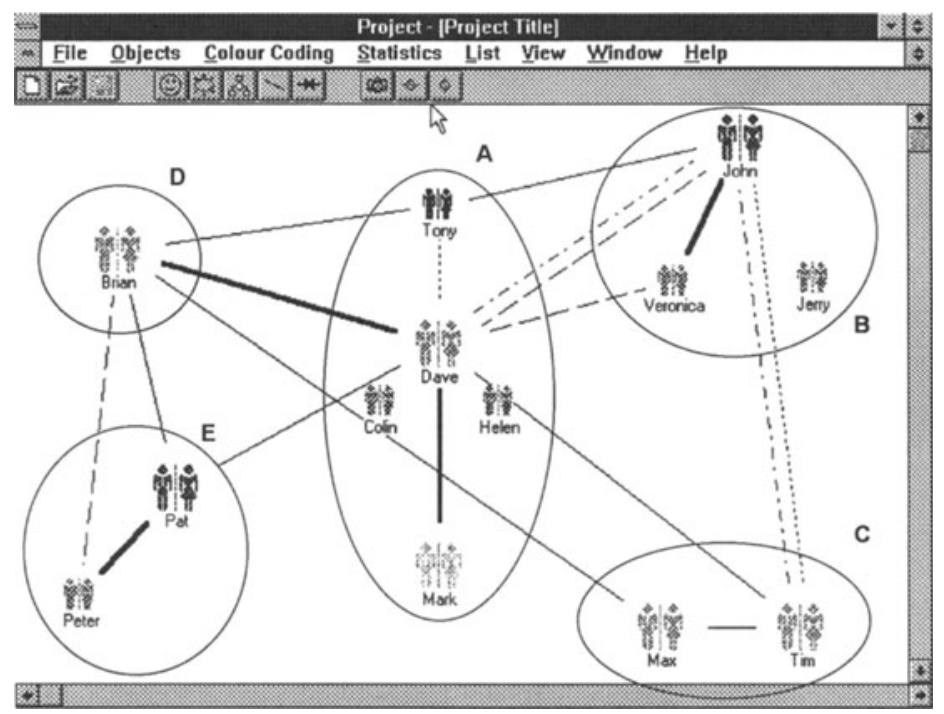

Figure 2 People involved in the system selection decision

Going to the other decisions of Table 1, the purchasing of goods from suppliers in the Far East is a good example of completely routinised decision, recurring every month and regularly involving large volumes of goods. This involved Dave and Colin getting together and making predictions for the volumes required in the coming months. Once they had reached a decision as to how much to order of each product, they clear their decision with Tony. The task of implementing the decision - including the monitoring of the movement of the goods through the Suez canal and into Rotterdam harbour - was left to Dave. The most striking characteristic of this decision was that it was made under considerable uncertainty and was often modified at the last minute based on little more than personnel hunches from either Dave, Colin or Tony. 
This decision group was very complex as it included the apparently best connected managers in the organisation (according to the current organisational network developed in OA) and they all contributed their personal sources of information to the predictions of required volumes of product. But Tony (the Managing Director) often had the final say in this matter.

The purchase of the telephone system was completed by Mark from the analysis of the requirements to the purchase of the complete solution. The only support he got in this decision process was the go-ahead to spend $£ 20,000$ which was given by Tony (the MD for Fun Ireland) and Veronica (the vice-president for Finance in the US). Throughout the decision process, Mark was in contact with a number of potential suppliers, but he focused on one particular supplier very early on in the decision process. This decision was less interesting from the point of view of this study insofar as it only involved two individuals, the decision owner (Mark) and the decision taker (Tony).

The decisions regarding new products and new markets rarely involved many people. The exploration of new horizons was handled mostly by Tony, Colin (the Marketing director for Fun in Ireland) and his assistant. They initiated the contacts with new distributors and advertising agencies abroad. These complex decisions were made on the basis of very specific and accurate simulations of the potential contribution of each product on each market which enabled Fun to make an educated guess concerning the financial potential of new targets. These simulations were prepared by Dave and Mark who are often seen as the Lotus 123 wizards in Fun and then refined by Colin who had a better knowledge of the markets. An example of how short the decision loop could become if an opportunity arose was given recently when the launch of an existing product in Spain was initiated by Colin who sought and obtained the approval of Tony in one meeting and committed large amounts of product to this new market. This quick decision turned out to be very successful and enabled the company to perform well above its targets for the year.

Finally, the decision to acquire another company in Europe could not be included in Organisation Analyser for reasons of secrecy. Indeed, it proved difficult to identify how the decision had unfolded (it was only made public once the contracts had been signed so the data collection could only be historical and superficial). It was nevertheless possible to identify that mainly five people (John, the Chairman of the board for the parent company, three vicepresidents from the HQ in the US and Tony, the MD for Fun Ireland) were involved with the merger on Fun's side. According to the Irish Managing Director, the decision was extremely difficult and took a lot of time. The same care and slow approach was adopted for other decisions that had to be made as a result of the merger - eg: the people to let go, the people to keep and the autonomy to be given the newly acquired organisation. Tony said that this care was a result of the decision makers feeling that they were on 'new ground' where they had never been before and were 'experimenting' with the decision making process as it went along.

\section{Findings of the Case Study at Fun}

The decision groups studied in Fun turned out to be of variable size from nearly 20 people disseminated in four organisations for the selection of the CBIS to just 2 in the case of the purchase of the telephone system. This reflects the small size of the managerial group and the high degree of specialisation of the managers in Fun. This was a general characteristic in Fun where all the staff, managers and employees, have developed extremely personal and effective 
work practices in their positions and would be difficult to replace. Thus, the decision groups studied often involved the same people, but in radically different positions and roles.

This preliminary finding highlights the major difficulty in applying the principles of network analysis to the study of organisational decision making. Many attributes of the actors involved in the management of an organisation (eg: classification as support node or primary node, degree of centrality) are not stable and change drastically depending upon the focus of research. As coded in OA, a manager can be quite central and important in the context of a decisional network (the sub-network dealing with that decision), while being a mere support node or not being involved at all in other sub-networks. This was the case for Mark who was decision owner in one case and not connected in other cases, but also for Dave and Colin who were decision centres for a number of decision processes and were nevertheless excluded from the merger decision. This indicates the very relative nature of the concept of centrality in organisations as it can be visualised in OA. Being well connected to a lot of people is certainly a desirable attribute, but it does not confer decisional power. It gives a manager the potential to play an important role in the management of an organisation, but this potential can only be enabled by a prominent position in the formal structure of the organisation and by a positive reputation in the organisation for being a 'problem-solver' or having the proper skills. OA's main strength is that it allows the coding of the 'version' of the network which is activated by each specific decision within the overall organisational network.

When coding the global network of an organisation in OA, the researcher must interpret his or her overall knowledge of the organisation's activities to evaluate the role of a given manager. At the level of specific decisional networks, the role and centrality of each manager is entirely dictated by the actual processes observed. Organisation Analyser enables the researcher to break down the overall network to begin the investigation at a finer level of analysis, that of the decisional group. Thus, OA supports the coding of a sample of decisional groups and the aggregation of all this (sometimes contradictory) information into the organisational network. This confirms the validity of the methodology developed for this research project:

1) selection of a sample of decisions representative of current organisational processes

2) use of OA to switch from one analytical level to the next in an effort to get a complete picture of decision making in the organisation studied.

OA proved particularly useful in the analysis of structural holes. By their very nature, structural holes are very unlikely to appear at the level of decisional groups. In most cases, the formal structure of organisations ensures that decisions are dealt with by well-connected groups of people. Structural holes appear mainly when the organisational network is considered in its entirety and areas of decision making appear to be isolated. This causes the coordination of these different groups to be loose and can results in wrong decisions being made that clash with each other at implementation stage. In Fun, the communication between the headquarters (in the US) and the Irish subsidiary seemed very weak. This was not due to a lack of communication channels, but more to a reluctance from the part of the managers in the US to exchange their views with their Irish counterparts. It is the author's perception that this lack of clarity in the exchanges of information, which is obvious in OA (see Figure 2 where only Tony has real communication links with US managers), amounts to a 'purposeful' structural hole created and maintained by some of the top managers at the interface between 
the two entities. It would seem that Tony (who was also a member of the Board for Fun International) did not always disseminate all the information in his possession to his subordinates.

This structural hole identified at the overall level was found to cause a break-down of communication within the decisional group involved with the purchase of the CBIS. This can explain to a large degree why this decision process appears so difficult. Overall, this decision will have taken two and a half years to select a system which is now only implemented in slow motion. According to Eisenhardt (1990) and Carlsson (1993), this is the sign of a very uncertain company where decision making suffers from the lack of clarity of the goals or the lack of decisiveness of managers. Such companies, they say, are generally unable to make fast and accurate decisions and often fail to adapt to their environment. Carlsson gives the three characteristics of good decision making: a quick yet rational decision process, a decisive powerful CEO yet an equally empowered top management team and a bold yet safe incremental execution. These three characteristics appeared to be missing at Fun which was confirmed by the very long time it had taken to purchase Kiddies, the complementary company in the UK. That seemed to indicate that decision making was a slow process in Fun.

In fact, it can be argued that these two decision processes are not characteristic of the decision making in Fun for two different reasons. The purchase of the CBIS is the consequence of the structural hole mentioned above and the purchase of Kiddies constituted too radically new an adventure for Fun's managers. Indeed, a look at the other decisions in the sample, especially the decisions on the upper level of the framework which by their nature are recurrent decisions (even though they might occur only once a year) revealed that Fun was primarily a very fast and decisive organisation, quite in line with Carlsson's (1993) recommendations. In the areas where they felt confident that they understood the issues at hand, managers at Fun were very sharp. They never spent undue time debating whether to reorder from their Far East suppliers even though these purchasing decisions were of the order of a hundred thousand pounds. They would purchase several containers of goods in preparation for the launch of a new advertising campaign in any of the European markets and the goods could end up anywhere in Europe, pushed by the very strong marketing policies of the companies. The procurement policy was so aggressive that sales representatives were never short of stocks, but lasting situations of over-stock never seemed to occur in Fun.

Similarly, the decisions to expand to new markets were always taken very fast. Quantities were ordered, or sometimes they were available due to the relative failure of an advertising campaign in another market, and they were committed in one meeting and shipped to the distributors. When a market was completely new, the Managing Director and the Marketing Director would travel there and spend several weeks negotiating with potential distributors and creating reliable contacts and sources of feed-back for the monitoring of the launch on the new market. Procedures for such important moves were well-established and efficient and involved a small number of people used to working together. At times, it seemed like this group of executives displayed signs of Groupthink or feelings of invulnerability as described by Janis (1972), but the obvious, consistent success of the current strategy leaves no doubt as to how well managers at Fun understand their markets and their products. 


\section{Discussion of the Findings}

These observations indicate that the presence of structural holes in organisations can cause decision making processes to break down or, at least, to slow down to a great extent. Furthermore, they suggest that structural holes have more to do with top managers' personal styles than with organisational structure. Analysis of the data coded in OA showed that it was up to a number of key individuals to remove the distortion in the network, but the sensitive nature of this issue did not allow the researcher to even attempt to clarify whether the individuals in question were aware of this distortion.

The findings also confirm that the degree of familiarity of managers with the problems they address is paramount in explaining the speed and the directness of the approaches used by organisations to adapt to their environment and make good decisions. In Fun, the recurring decisions regarding the products and markets were made with great certainty and great speed because the decision groups concerned by these decisions had developed a set of common behaviours and managerial tools that all managers understood and trusted to be appropriate. Two conditions seemed to be required for an organisation to benefit from the degree of familiarity of the team with a decision situation: (1) tools and procedures had to be developed that would become the accepted way to approach a problem and (2) once these techniques were developed, they had to be used consistently, not only to analyse future decisions, but also to analyse past decisions and review their outcomes. This was a readily identifiable form of organisational learning at Fun and one that gave great confidence to the managers when making their decisions. Such systematic review of the outcome of previous decisions proved crucial at Fun in enabling managers to keep up with their markets and products.

However, there was another reason why the decision making at Fun was so fast and aggressive for these recurrent decisions. The common point between all the decisions in the upper area of Table 1 (the recurrent decisions) is not only that they had occurred before, but that their outcome is reversible. In other words, the consequences of making a wrong decision are not perceived as being fatal for the company. In this instance, reversibility does not mean that managers feel confident that they can reverse the decision made and return to the previous state (this is almost never possible), but that they know that they will find alternative solutions if the future they had planned does not materialise. For example, the ease with which managers at Fun ordered big consignments of goods was justified by the existence of alternative markets where products can be shipped if the targeted market fails. Similarly, the decision to create a new product is not as important and difficult when toys are involved as when a new model of motorcar is concerned. A bad toy can be discarded, whereas a new car must be a success. The importance of the outcome of a decision was confirmed by the difficulties met by Fun's managers in relation to the probably irreversible merger decision.

Finally, the analysis of the decision groups at Fun based on the sub-networks coded in OA also indicated that all managerial groups seem to be organised around a central individual who becomes the owner of that decision (this phrase is actually used in Fun to describe the manager in charge of leading and implementing a project). This was the case with Dave for two of the decisions (the purchases from the Far East and the system selection), Mark for the purchase of the telephone system, Tony or Colin for the new markets and John for the merger. We have already described above the boundaries of the concept of centrality. Centrality is an essential characteristic of leadership, but it is not a stable characteristic in organisational networks. In fact, the centre of the decision groups was found to vary with the different decision situations 
as most decisions had a different leader. However, this were only true for the decision owners - i.e.: the people who lead the decision from start to finish either that they had volunteered to be project leaders or that they had been assigned the supervision of the decision. It did not hold for the overall control of the decision making process as all decisions were ultimately confirmed or approved by the same one or two people at Fun: John, the Chairman of Board in the US or Tony, the Managing Director for Ireland. In that sense, if decision leadership was variable and project based, decision taking was always centralised around the same people even though many other decision makers were heavily involved in managing and leading projects in the organisation. In particular, Dave and Colin were frequent decision owners because they were very active managers, but they often had to seek approval from Tony or to the vice-presidents in the US for important matters. In that sense, the analysis enabled by OA reveals that the concept of centrality as it has been described in the network literature ignores the reality of power in organisations. This highlights that the role of a top manager may often be that of a referee who accepts or rejects decisions that have already been designed by others rather than the more active role of shaping the decisions made by an organisation.

\section{CONCLUSIONS}

A lot of the research in management and in IS has focused on one specific aspect of organisational life such as decision making, communication, information processing or information interpretation. Very often this research has been aimed at developing normative processes and few studies have provided complete pictures of the activities involved in management. One of the reasons for this was highlighted by Nutt (1984) who stated that organisational processes are made up of so many activities that researchers are faced with a dilemma. Either they use a strict framework which they use to collect data on a large number of cases (ability to generalise the findings) or they use an emergent approach to examine the raw data of a small number of cases and use their intuition to find patterns, phases and sequences (richness and completeness). Both approaches have weak points as an artificial order may be imposed on what is essentially a chaotic process (framework based approach) or as the generalisability of the conclusions is somewhat sacrificed because the analysis of large data banks cannot be tackled (emergent approach).

The aim of this research project was to study the decision making processes used by managers in one organisation with the support of Organisation Analyser, a computerised tool based on a network approach to organisations which enables the collection and analysis of large volumes of data arising from an in-depth case study. The benefits of using such tools as $\mathrm{OA}$ are that they allow the consistent and rigorous comparison of data within cases - ie: across decisional groups, and across case studies of different organisations (which is the next step in this research project). Furthermore, OA enables researchers to begin their inquiry at a realistic analytical level, that of the decisional groups with the view to building up their knowledge of the overall network of an organisation incrementally and meaningfully. This seems to be a feasible way to reach reliable and generalisable conclusions regarding an organisation's decision making processes.

The preliminary findings reported in this paper confirm the benefits of using an approach based on the analysis of the decisional networks in organisations. In particular, the analysis of 
the concepts of centrality, decision ownership and decision authority in organisational decision making processes reveals a complex picture likely to confuse research results obtained if the decisional networks in existence were ignored. In Fun, the decision leadership was delegated to a large extent and the decisional groups evolved dynamically as the decisions unfolded, but overall control remained in the same hands whatever the decision.

Structural holes were found to have a great importance for the efficiency of organisational processes. OA turned out to greatly facilitate the identification of these accidental or purposeful discontinuities in the network of organisations. In supporting the identification of distortions and discontinuities in the networks of organisations, OA proved its potential as a DSS type tool to assist managers in identifying and removing the weaknesses in the formal and informal networks of their organisations. Thus, OA becomes a simulation tool, a kind of decision support system to study the shaping and reshaping of the organisation as it faces a variety of situations likely to heighten tensions, to create uncertainty or to require commitment to radically new policies. Such a tool seems particularly useful to researchers of organisation phenomena, but with some further developments of the interface and of the accuracy of the diagnostic it can formulate on an organisation's processes, OA could become a valuable managerial tool to evaluate the suitability of the current structure of an organisation and explain the difficulties encountered by some managers. Already, OA has demonstrated its potential in enriching the communication between the researchers and the people they interview as it enables interviewees to visualise how "their" data was interpreted by the researchers.

Another important finding for the continuation of this research was that the novelty of the problem, its specificity and the reversibility of the outcome are three fundamental dimensions for the study of decisions. Thus, Adam et al.'s framework (1995), which was used in this study for the selection of a sample of decisions, must be augmented so as to take into account the reversibility of the outcome of a decision in addition to the novelty of the problem and its specificity.

This project must now continue and investigate more companies and more decision processes until data covering a large sample of both decisions and organisations are available to the researcher and reliable and generalisable conclusions can be drawn on the issues identified in this paper.

\section{REFERENCES}

Adam F. and Murphy C. (1995 a) Information flows amongst executives: their implications for systems development, Journal of Strategic Information Systems, 4(4).

Adam, F. and Murphy, C. (1995 b) Organisation Analyser - A Computer-Based Tool to Support The Analysis of Organisations from an Information Perspective, Proceedings of the third SISnet Conference, Bern, September 1995, 1-19.

Adam, F., Fahy, M. and Murphy, C. (1995) Cumulative research in decision support systems a practical example, Proceedings of the Third Conference on Information Systems (ECIS), Athens, June 1995, 1221-1233.

Balbridge J. V. (1971), Power and Conflict in the University, Wiley, New-York. 
Bales, R. F. (1950) Interaction Process Analysis: A Method for the Study of Small Groups, Cambridge, MA: Addison-Wesley, 1950.

Bales, R. F. (1953) The equilibrium problem in small groups. In T. Parsons, R.F. Bales and E.A. Shils (Eds), Working Papers in the Theory of Action. Glencoe, IL: Free Press, 1953.

Blandin, J.S. and Brown, W.B. (1977) Uncertainty and management's search for information, IEEE Transactions on Engineering Management, EM24, 114-119.

Brass Daniel J. and Burkart Marlene E. (1992) Centrality and power in organisations, in Nitin Nohria and Robert Eccles (Eds.) Networks and Organisations: Structure Form and Action, Harvard Business School Press, Boston Mass, Chapter 7.

Burt, R. S. (1980) Models of Network Structure, Annual Review of Sociology, 6, 79-141.

Burt, R. S. (1992) The social structure of competition, Nitin Nohria and Robert Eccles (Eds.) Networks and Organisations: Structure Form and Action, Harvard Business School Press, Boston Mass.

Carlsson S. A. (1993) Executive support systems for executive teams in organisations in highvelocity environments, Proceedings of the Twenty-six Annual Hawaii International Conference, III, 1-20.

Daft, R. L. and Lengel R. H. (1986) Organisational information requirements, media richness and structural design, Management Science, 32(5), 554-571.

Daft, R.L., Sormunen, J. and Parks, D. (1988) Chief executive scanning, environmental characteristics and company performance: an empirical study, Strategic Management Journal, 9, 123-139.

Eisenhardt Kathleen M. (1990) Speed and strategic choice: how managers accelerate decision making, California Management Review, 31, 39-54.

Euske, N. and Roberts, K. (1987) Evolving perspectives in organisation theory: communication implications, in Jablin, F., Putnam, L., Roberts, K. and Porter, L. (eds.) (1987) Handbook Of Organisational Communication: An Interdisciplinary Perspective, pp. 41-69.

Feldman M. and March J. (1981) Information in organisations as signal and symbol, Administrative Science Quarterly, 26, 171-186.

Gorry A. and Scott Morton. M. (1971) A Framework for Management Information Systems, Sloan Management Review, Fall, 55-70.

Granovetter, MS(1973) The strength of weak ties, American Journal of Sociology, 78, 13601380

Hedberg, Bo (1981) How organisations learn and unlearn, Nystrom, P.C. and Starbuck, W.H. (Eds.) Handbook of Organisational Design, 2, Oxford University Press, England, 3-27.

Huber G. (1982) Organisational information systems: determinants of their performance and behaviour, Management Science, 28(2), 135-155.

Huber, G. and McDaniel, R. (1986) The decision-making paradigm of organisational design, Management Science, 32, Number 5, pp. 572-589.

Janis, I. L (1972), Victims of Groupthink, Houghton Mifflin Comp, USA.

Jones J Saunders C and McLeod R (1988) Information media and source patterns across management levels: A pilot study, Journal of Management Information Systems, 5(3), 71-84.

Kadushin C. (1978) Small world - How many steps to the top?, Detroit News, 106(26). 
Keegan, W. (1974) Multinational scanning: a study of the information sources utilised by headquarters executives in multinational companies, Administrative Science Quarterly, 411-421.

Keen, P.G. (1977) The evolving concept of optimality, in Starr and Zeleny (Eds.), TIMS studies in Management Science, 6, North Holland, 31-57.

Keen, P.G. and Scott Morton, M.S. (1978), Decision Support Systems: An Organisational Perspective, Addison-Wesley, Reading, Mass.

Kefalas, A. (1973) Scanning the business environment - some empirical results, Decision Science, 4, 63-74

Le Bon, G. (1896), The Crowd - A Study of the Popular Mind, Fisher Unwin, London.

Lévine, P. and Pomerol, J.C. (1995) The role of the decision maker in DSSs and representation levels, in Nunamaker and Sprague (Eds.) Proceedings of the 28th Annual Hawaii Conference on System Sciences, 1995, 42-51.

March, J.P. (1981) Footnotes to organisational change, Administrative Science Quarterly, 26, 563-577.

March, J.P. (1987) Ambiguity and Accounting: the elusive link between information and decision making, Accounting, Organisations and Society, 12(2), 153-168.

March, J.P. and Olsen, J.P. (1989), Rediscovering Institutions - The Organisational Basis of Politics, The Free Press, New York.

March, J.P. and Olsen, J.P. (1986), Garbage can models of decision making in organisations, in J. March and R. Weissinger-Baylon (eds.) Ambiguity and Command: Organisational Perspectives on Military Decision Making, 11-35.

March, J. and Simon, H. (1993), Organisations, (2nd edition), Blackwell Publishers, Cambridge, Mass..

McGraph, Joseph E (1984), Groups - Interaction and Performance, (1st Edition), PrenticeHall, Englewood Cliffs, N.J. 07632.

Mintzberg, H. (1973) The Nature Of Managerial Work, Prentice Hall.

Mintzberg, H., Raisinghani, D. And Théorêt, A. (1976) The Structure of "Unstructured" Decision Processes, Administrative Science Quarterly, 21, 246-275.

Monge P. and Eisenberg E. (1987) Emergent communication networks, in Jablin F. Putnam L. Roberts K. and Porter L. (eds.) Handbook Of Organisational Communication: An Interdisciplinary Perspective, Sage Publication, London, 41-69.

Moore, J.H. and Chang, M. (1983) Meta-Design considerations, in J.L. Bennett (Ed.), Building Decision Support Systems, Addison-Wesley, 173-204.

Nohria N. (1992) Introduction: Is a network perspective a useful way to studying organisations, in Nitin Nohria and Robert Eccles (Eds.) Networks and Organisations: Structure Form and Action, Harvard Business Scholl Press, Boston Mass.

Nutt, Paul C. (1984) Types of organisational decision processes, Administrative Science Quarterly, 29, 414-450.

O'Reilly, C., Chatman, J. and Anderson, J. (1987) Message flow and decision making, in Jablin, F., Putnam, L., Roberts, K. and Porter, L. (eds.) (1987) Handbook Of Organisational Communication: An Interdisciplinary Perspective, 600-623.

Pennings, J. M. (Ed.) (1983), Decision Making: An Organisational Behaviour Approach, Weiner, New York. 
Pomerol, J.C. (1994) Des preferences au choix, des mathematiques a l'intelligence artificielle: le monde de l'aide a la decision, LAFORIA report 94 / 20, University Pierre et Marie Curie, Paris.

Roetlisberger F. J. (1977), The Elusive Phenomena, Harvard Business School Press., Boston.

Roetlisberger F. J. and Dickson W.J. (1939), Management and the Worker, Harvard University Press., Cambridge.

Simon, H. (1955), A behavioural model of rational choice, Quarterly Journal of Economics, 69, 99-118.

Simon, H. (1977) The New Science of Management Decisions, Prentice Hall.

Stohl, C. and Redding, W. (1987) Messages and message exchange processes, in Jablin, F., Putnam, L., Roberts, K. and Porter, L. (eds.) (1987) Handbook Of Organisational Communication: An Interdisciplinary Perspective, 451-502.

Tichy N. M. (1992) Networks in organisations, in Nitin Nohria and Robert Eccles (Eds.) Networks and Organisations: Structure Form and Action, Harvard Business Scholl Press, Boston Mass, Chapter 10.

Tichy, N. M. (1981) Networks in organisations, Nystrom, P. and Starbuck, W. (Eds.) Handbook of Organisational Design, 2, Oxford University Press, New York, 225-249.

White H. C. (1992) Agency as control in organisational networks, in Nitin Nohria and Robert Eccles (Eds.) Networks and Organisations: Structure Form and Action, Harvard Business Scholl Press, Boston Mass, Chapter 3.

\section{BIOGRAPHY}

Frédéric Adam is college lecturer in the Department of Accounting, Finance and Information Systems at University College Cork in Ireland. He is also a senior researcher with the Executive Systems Research Centre. His main research interests include the usage of information in organisations and the study of research methodologies in the IS field. His research has been published in a number of journals including the Journal of Strategic Information Systems and he has presented his work in several recent IS conferences in Greece, Holland, Ireland and Switzerland. He is also involved in a number of consultancy projects in the area of information systems implementation and information systems for top managers.

The author would like to acknowledge the contribution of Brian Fitzgerald, Ciaran Murphy and Jean-Charles Pomerol. 